\title{
Application of Waste Polymers as a Raw Material for Ultrafiltration Membrane Preparation ${ }^{+}$
}

\author{
Michał Adamczak*, Gabriela Kamińska and Jolanta Bohdziewicz \\ Institute of Water and Wastewater Engineering, Silesian University of Technology, Konarskiego St. 18 \\ Gliwice 44-100, Poland; gabriela.kaminska@polsl.pl (G.K.); jolanta.bohdziewicz@polsl.pl (J.B.) \\ * Correspondence: michal.adamczak@polsl.pl; Tel.: +48-32-234-27-77 \\ + Presented at Innovations-Sustainability-Modernity-Openness Conference (ISMO'19), Bialystok, Poland, \\ 22-23 May 2019.
}

Published: 12 June 2019

\begin{abstract}
Currently, polymer membranes are widely used in water treatment processes. The polymers commonly used for their production are polysulphone, polyacrylonitrile, or polyethersulphone. However, there are many other raw materials from which membranes can be prepared. In this work, polystyrene membranes were obtained by dissolving Styrofoam in dimethyleformamide. The surface properties of the obtained membranes differed slightly from those obtained for polymer membranes prepared from typical granulates. Retention testing in ultrafiltration conditions showed that membranes made form waste polystyrene have similar parameters to membranes made from pure polymers.
\end{abstract}

Keywords: membranes; ultrafiltration; waste; polystyrene

\section{Introduction}

Polystyrene is a polymer commonly used in architecture as Styrofoam for building isolation. It also has applications as packaging for glass and sensitive products like electronics, household products, and other goods. Single-use products like cups and plates are important for waste management [1]. A new idea for the application of Styrofoam waste is to use it as a raw material for water reclamation. At present, different, non-waste polymers like polysulphone, poly(ether sulphone), polyacrylonitrile, polyvinylidene fluoride, and others are used for membrane preparation [2]. The use of polystyrene for this purpose is negligible. One of the available works touching on this subject was published in 2008 [3].

\section{Materials and methods}

Styrofoam waste as a raw material was taken from packaging filler and food packaging. Surface water from the Kłodnica river in Katowice was chosen as the feed. Casting solutions were prepared from Styrofoam and $N, N$,-dimethylformamide in three different concentrations: $16 \%, 18 \%$, and $20 \%$. The properties of the membranes were tested: porosity was determined by a gravimetric method, hydrophobicity and hydrophilicity were determined using a goniometer, and the thickness was measured in micrometers. Filtration tests were conducted in an Amicon ${ }^{\circledR}$ system (Merck Millipore, Billerica, MA, USA) under 0.1 MPa of pressure. The permeate was collected and the values of pollution indicators were measured and compared to the values in surface water. The $\mathrm{pH}$ and conductivity were measured using a $\mathrm{pH}$ meter and conductometer, respectively. The color, turbidity, nitrates, and phenol index were measured using a Spectroquant ${ }^{\circledR}$ Pharo 100 spectrophotometer (Merck Millipore, Billerica, MA, USA) connected with a TR 620 thermoreactor. The absorbance was also tested. 


\section{Results}

For pristine membranes, the angle of wettability of the membrane, regardless of which membrane, was in the range of 50 to $60^{\circ}$. All membranes were described as rPS (recycled polystyrene) with number which means wt. \% contribution in casting solution. As can be seen in Table 1, the results obtained in the porosity tests for the rPS 18 and rPS 20 membranes assumed values ranging from about $57 \%$ to $62 \%$; thus, they show a similar pressure characteristic. The rPS 16 membrane had a different porosity, below $40 \%$, which directly caused its low permeability at low pressures from 0.05 to $0.1 \mathrm{MPa}$, as seen in Figure 1 .

Table 1.Contribution of ingredients in the casting solution.

\begin{tabular}{ccc}
\hline Membrane Type & Porosity (\%) & Contact Angle (\%) \\
\hline rPS 16 & $38.52 \pm 2.27$ & $53.30 \pm 3.98$ \\
rPS 18 & $62.47 \pm 3.11$ & $49.60 \pm 4.86$ \\
rPS 20 & $57.10 \pm 5.31$ & $58.50 \pm 5.50$ \\
\hline
\end{tabular}

In the retention tests conducted, reductions in all indicators were achieved for membranes with lower permeability. The permeability values are presented in Figure 1. This phenomenon has been widely observed, for example, by Tiron et.al. [3]. The highest reduction levels in all membranes were observed for color and turbidity of around 60\%-80\%. Reduction levels around the mean were observed for phenol index and absorbance of around $20 \%-45 \%$. Phenols have low molecular weight and should not be removed in low-pressure membrane techniques. However, these substances can be adsorbed by other, bigger particles or create complexes with them. The lowest reduction levels were observed to be related to nitrates and conductivity. Reductions in these indicators were not possible for substances relating to these parameters because of their low molecular weight. In contrast to phenols, they are not able to create bigger particles or be adsorbed by other high-molecular-weight substances. Conductivity is a parameter connected with salts dissolved in water. Salts and nitrates are removed only in a reverse osmosis process [4,5].

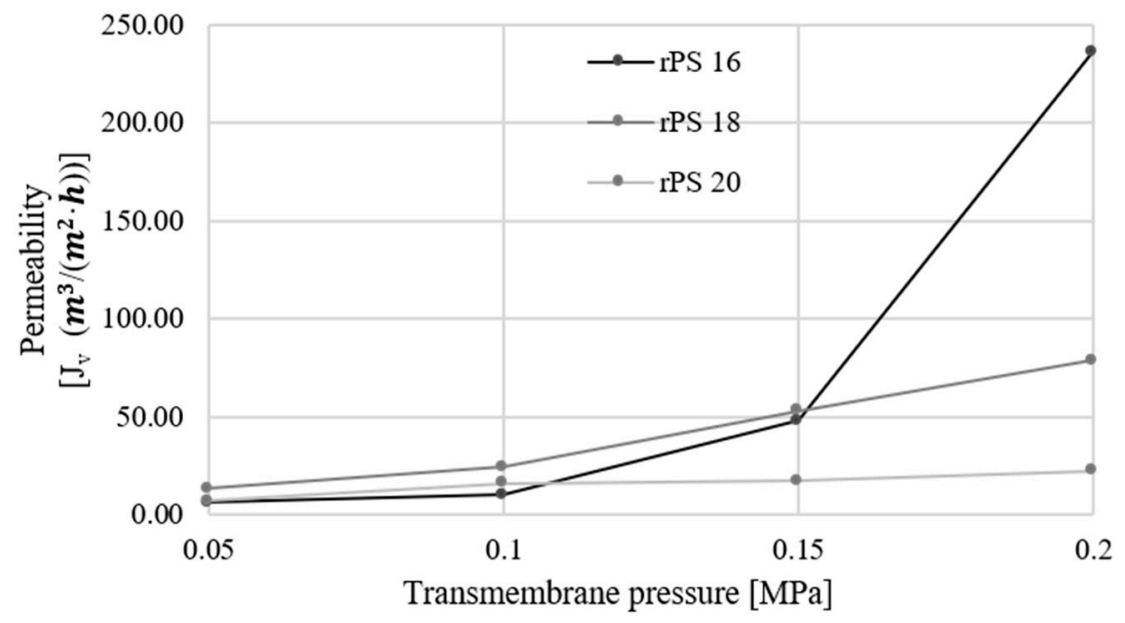

Figure 1. The permeability of the prepared membranes relative to transmembrane pressure.

\section{Conclusions}

The achieved results concerning the membranes' surface properties and retention levels suggest that polystyrene can be used as a raw material for ultrafiltration membrane preparation. The transport and surface properties of these membranes are similar to those in the results achieved in other works with poly(ether sulfone) membranes. The high level of rejection of phenols may be evidence of the high potential of these membranes for removal of this kind of pollutant. The properties of these membranes may also be improved by the implementation of nanocomposites [6]. 
The use of Styrofoam as a raw material decreases the costs of membrane preparation and will contribute to a smaller amount of waste being generated in the laboratory.

Author Contributions: M.A. and J.B. conceived and designed the experiments; M.A. performed the experiments; G.K. analyzed the data and contributed reagents/materials/analysis tools; M.A., G.K. and J.B. wrote the paper.

Acknowledgments: The work was created as a result of the research project titled "Preparation of membranes from waste polymers" as part of statutory research No. BK-259/RIE-4/2018.

Conflicts of Interest: The authors declare no conflict of interest.

\section{References}

1. Truchan, K.; Wyszyńska, E. Styropiany nie muszą zaśmiecać. Przegl. Bud. 2008, 12, 49-52.

2. Chen, Z.; Rana, D.; Matsuura, T.; Yang, Y.; Lan, C.Q. Study on the structure and vacuum membrane distillation performance of PVDF composite membranes: I. Influence of blending. Sep. Purif. Technol. 2014, 133, 303-312, doi:10.1016/j.seppur.2014.07.015.

3. Ramos-Olmos, R.; Rogel-Hernandez, E.; Flores-López, L.; Lin, S.W.; Espinoza-Gómez, H. Synthesis and characterization of asymmetric ultrafiltration membrane made with recycled polystyrene foam and different additives. J. Chil. Chem. Soc. 2008, 53, 1705-1708, doi:10.4067/S0717-97072008000400015.

4. Tiron, L.G.; Pintile, S.C.; Lazar, A.L.; Vlad, M.; Balta, S.; Bodor, M. Influence of Polymer Concentration on Membrane Performance in Wastewater Treatment. Mater. Plast. (Bucharest, Rom.) 2018, 55, 95-98.

5. Ratajczak, P. Procesy membranowe-Wprowadzenie. Tech. Wod. 2013, 4, 16-20.

6. Kliber, S.; Wiśniewski, J.; Membranowy proces wymiany anionów jako metoda zmiany składu jonowego wody. Rocz. Ochr. Śr. 2009, 11, 995-1005.

7. Adamczak, M.; Kamińska, G.; Bohdziewicz, J. The effect of various conditions on the ultrafiltration process of bisphenol A using nanocomposite membranes modified with carbon nanotubes. E3S Web. Conf. 2018, 44, 1-7, doi:10.1051/e3sconf/20184400001 